\title{
İleri Evre Orofarenks Kanserli Bir Hastada Nekroze Enfekte Tümöral Kitlede Cedecea Lapagei Süperenfeksiyonu: Olgu Sunumu (Cedecea lapagei süperenfeksiyonu)
}

\section{Cedecea Lapagei Superinfection in a Tumoral Mass of Locally Advanced Oropharyngeal Carcinoma: a Case Report (Cedecea lapagei superinfection)}

\author{
Özgür TANRIVERDí ${ }^{1}$, Kerim Kaan SANDAL ${ }^{2}$, Sedef ATEŞ ${ }^{2}$, Selçuk UYLAŞ ${ }^{2}$, Hatice DUMAN ${ }^{3}$, \\ Ayşe Ferhan AKGÜL ${ }^{4}$, Ali ALKAN ${ }^{1}$
}

\begin{abstract}
${ }^{1}$ Muğla Sıtkı Koçman Üniversitesi Tıp Fakültesi Tıbbi Onkoloji Bilim Dalı, Muğla ${ }^{2}$ Muğla Sitkı Koçman Üniversitesi Tıp Fakültesi, Muğla

${ }^{3}$ Muğla Sıtkı Koçman Üniversitesi Tıp Fakültesi İç Hastalıkları Anabilim Dalı, Muğla ${ }^{4}$ Muğla Eğitim ve Araştırma Hastanesi, Enfeksiyon Hastalıkları Kliniği, Muğla

Öz bir üyesi olan Cedecea cinsi bakteriler ciltte normal florada bulunmazlar ancak gastrointestinal sistemde kolonize olabilirler. Buna karşın klinik önemleri henüz net değildir. Sıklıkla immunsupresyonu olan hastalarda gelișen Cedecea enfeksiyonlarının nadir olduğu belirtilmiştir. Literatürde bakteriyemi, abse, ülser, idrar yolu, pnömoni, göz ve yara enfeksiyonları nadir olgular olarak bildirilmiştir. $\mathrm{Bu}$ yazıda sisplatin, 5-fluorourasil, setuksimab anti-kanser ilaçlarından oluşan kombinasyon rejimi ile tedavi edilen ileri evre orofarenks skuamöz hücreli karsinom tanılı erkek hastada gelişen C. lapagei

\section{Abstract}

Cedecea type of bacteria that is isolated from sputum and a member of Enterobacteriaceae is not found in skin flora. However, it may be colonised in the gastrointestinal system. On the other hand, the clinical importance of it has not been well documented. It has been rarely reported in immunosuppressive individuals. In literature, it is reported that bacteraemia, abscess, ulcer, urinary tract infection, pneumonia, eye and wound infections associated with Cedecea lapagei are the rare cases. Here, were present a Cedecea lapagei related wound infection in a locally advanced oropharyngeal squamous cell carcinoma treated with cisplatin, 5-fluorouracil and cetuximab.
\end{abstract} yara enfeksiyonu sunulmuştur.

Anahtar Kelimeler: Cedecea Lapagei, Cedecea Türleri, Yara Enfeksiyonu

\section{Giriş}

1980 yilinda "CDC Enterik Grup 15" ismi ile Enterobacteriaceae ailesinin bir üyesi olarak kabul edilen Cedecea cinsi, ilk defa 1977 yılında Amerika Birleşik Devletleri hastalık kontrol ve önleme merkezi (CDC) laboratuvarlarında izole edilmiştir $(1,2)$. Laktoz negatif, katalaz pozitif, fakültatif anaerob, spor oluşturmayan ve hareketsiz gram negatif basiller olan bu bakteriler, günümüzde C.davisae, C.lapagei, C.neteri, Cedecea 3, Cedecea 5 ve Cedecea 6 olmak üzere altı farklı tür içerir (14). Cedecea cinsi bakterilerin lipaz pozitif, sefalotin

\begin{tabular}{ll}
\hline Özgür TANRIVERDİ & ORCID No \\
Kerim Kaan SANDAL & $0000-0002-0598-7284$ \\
Sedef ATEŞ & $0000-0001-2315-9706$ \\
Selçuk UYLAŞ & $0000-0002-6120-4782$ \\
Hatice DUMAN & $0000-0003-4545-659 X$ \\
Ayşe Ferhan AKGÜL & $0000-0003-0834-3094$ \\
Ali ALKAN & $0000-0002-8253-5046$
\end{tabular}

Başvuru Tarihi / Received: 01.07.2019

Kabul Tarihi / Accepted : 14.10.2019

Adres / Correspondence : Özgür TANRIVERDİ

Muğla Sitkı Koçman Üniversitesi Tıp Fakültesi Tıbbi Onkoloji Bilim Dalı, Muğla

e-posta / e-mail

dr.ozgur.tanriverdi@gmail.com
Keywords: Cedecea Lapagei, Cedecea Species, Wound Infection ve kolistine dirençli olmaları bakımından Serratia cinsi ile benzer özelliklere sahip olduğu bildirilmiştir (1-5). Ancak jelatin ve DNA'y1 hidrolize etmedikleri için Serratia türlerinden ayırt edilirler $(1,2)$.

Cedecea türlerinin klinik önemleri henüz net değildir ve sıklıkla balgamdan izole edilirler (1-4). Buna karşın literatür bilgileri incelendiğinde, bazı vücut bölgeleri ve sıvılarında patojen olarak izole edilmiş olmalarına karşın nadiren bakteriyemi veya abseye neden oldukları görülür (2-4). Normal cilt florasının bir elemanı değildirler ancak gastrointestinal sistemde kolonize olabildikleri bildirilmiştir $(2,5,6)$. Bu nedenle izole edilse bile kaynağını belirlemek oldukça güç olabilir (2).

$\mathrm{Bu}$ yazı ile ileri evre orofarenks skuamoz hücreli karsinom tanısı alan 57 yaşında erkek hastada nekroze tümöral kitle üzerinde gelişen $\mathrm{C}$. Lapagei'nin sebep olduğu yara yeri süperenfeksiyonu bildirilmiştir.

\section{Olgu}

Yaklaşık 8 ay önce tanı anında akciğer metastazlı evre 4 orofarenks skuamoz hücreli karsinom tanısı alan 57 yaşında erkek hastaya 14 günde bir olmak üzere sisplatin, 5-fluorourasil, setuksimab anti-kanser ilaçlarından oluşan 
kombinasyon rejimi başland. Tedavi ile akciğer metastazlarında ve solda submandibuler alanı kaplayan yaklaşık $7 \times 5 \mathrm{~cm}$ büyüklüğündeki kitlede $\% 60$ oranında regresyon sağlandı. Tedavisine stabil hastalık olarak devam edilen hastanın 8. kür tedavisinde submandibuler kitlenin üzerinde cilt bütünlüğü bozan tümöral nekrozun geliştiği tespit edildi. Hasta 9.kür tedavisinde submandibuler bölgede kokulu, akıntılı yara enfeksiyonu tespit edilmesi nedeni ile hastaneye yatırıldı (Resim 1).

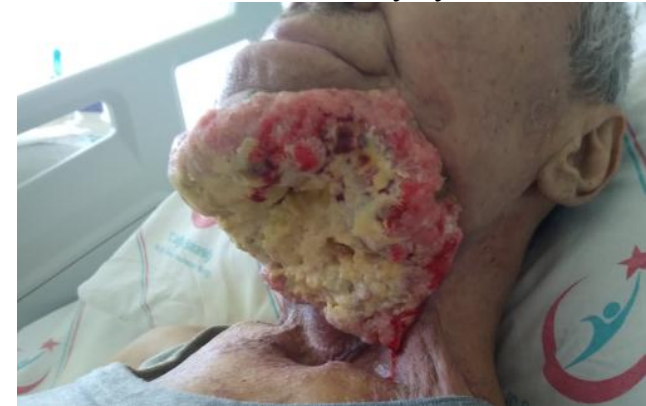

Resim 1. Orofarenks skuamöz hücreli karsinom tanılı hastada sol submandibuler alandan zigomatik bölgeye uzanım gösteren, 7 kür kemoterapi sonrasında nekrotik hale gelen tümöral kitle

Öncesinde herhangi bir sistemik kronik hastalık öyküsü ve halsizlik, iştahsızlık, sol çene altında ağrı haricinde şikayeti olmayan hastanın muayenesinde kan basıncı 110/60 mmHg, kalp hızı ritmik ve $84 / \mathrm{dk}$, solunum sayıs1 14/dk idi ve vücut 1sıs1 37.2 $\mathrm{C}$ olarak ölçüldü. Solunum sesleri her iki akciğer alt alanlarda kabalaşmıştı, sol periorbital ödem izlendi ve sol submandibuler alandan zigomatik bölgeyi de içine alacak şekilde uzanan $3.5 \times 4.1 \mathrm{~cm}$ büyüklüğünde ciltte sulanma, düzensizlik, eritem ve akıntı içeren, yer yer nekrozların izlendiği tümöral kitle palpe edildi. Kardiyovasküler sistem muayenesi normaldi, splenomegali, hepatomegali, lenfadenomegali, ikter ve ödem saptanmadi. Laboratuvar tetkiklerinde lökositoz $\left(14200 / \mathrm{mm}^{3}\right)$, nötrofili $\left(9980 / \mathrm{mm}^{3}\right)$, normositer normokrom anemi ( $\mathrm{Hb} 9.4 \mathrm{~g} / \mathrm{dL}, \quad \mathrm{MCV} 79 \mathrm{fL}$ ), trombositoz $\left(560.000 / \mathrm{mm}^{3}\right)$, artmış serum C-reaktif protein düzeyi (86 mg/dL), artmış sedimantasyon hızı (56 $\mathrm{mm} / \mathrm{saat})$, hipoalbuminemi (2.9 $\mathrm{g} / \mathrm{dL})$ haricinde patolojik bulgu izlenmedi.

Enfeksiyon hastalıkları konsültasyonu sonrasında yara yeri kültürü alındı ve amoksisilin/klavulanik asit (2x1000 mg/gün, peroral) ve amikasin (1x500mg, intravenöz) ile ampirik tedavisi başlandı. Kültür alındıktan üç gün sonra yara yerinde Pseudomonas fluorescens üredi ve hastanın tedavisi imipenem/silastatin (4x500 $\mathrm{mg} /$ gün, intravenöz) ve tigesiklin $(2 \times 50 \mathrm{mg} / \mathrm{gün}$, intravenöz) olarak düzenlendi. Klinik seyirde ateş yüksekliği, hemodinamik bozukluk ve yeni gelişen sistemik bir semptom izlenmeyen hastanın yatışı süresince alınan kontrol yara yeri kültürlerindeki üreme ve antibiyotik tedavileri Tablo 1'de özetlenmiştir. Yatışının 82.gününde yara yerinden alınan kültürde C. lapagei üreyen hastanın 98.günde genel durumu bozuldu ve hipotansiyon, taşikardi, şuurda bozulma izlendi ancak hasta yakınlarının isteği ve imzası ile evde bakılmak üzere hastaneden taburcu edildi.

\section{Tartışma}

Bu yazıda tümöral kitlenin nekroze yüzeyinde polimikrobiyal lokal yara enfeksiyonu gelişen ileri

Tablo 1. Orofarenks skuamöz hücreli karsinom tanılı hastada yatışının ilk gününden itibaren yara kültüründe izole edilen mikroorganizma ve uygulanan tedaviler

\begin{tabular}{|c|c|c|c|c|c|c|}
\hline Gün & Üreme & Antibiyoterapi & $\begin{array}{c}\text { Doz } \\
\text { (gün) }\end{array}$ & $\begin{array}{l}\text { Süre } \\
\text { (gün) }\end{array}$ & \multicolumn{2}{|c|}{$\begin{array}{l}\text { Duyarlı Olduğu } \\
\text { Antibiyotik Ajan }\end{array}$} \\
\hline 0 & Ampirik tedavi & AKA & $2 \times 1000 \mathrm{mg}$ & 3 & \multirow{2}{*}{\multicolumn{2}{|c|}{-}} \\
\hline & & Amikasin & $1 \times 500 \mathrm{mg}$ & & & \\
\hline \multirow[t]{2}{*}{3} & P. fluorescens & Imipenem/silastatin & $4 \times 500 \mathrm{mg}$ & 11 & Gentamisin & Seftazidim \\
\hline & & Tigesiklin & $2 \times 50 \mathrm{mg}$ & & Amikasin & İmipenem \\
\hline \multirow[t]{3}{*}{8} & P. aeruginosa & İmipenem/Silastatin & $4 \times 500 \mathrm{mg}$ & 2 & Netilmisin & Amikasin \\
\hline & & Tigesiklin & $2 \times 50 \mathrm{mg}$ & & Gentamisin & İmipenem \\
\hline & & & & & \multicolumn{2}{|c|}{ Kolistin } \\
\hline \multirow[t]{2}{*}{29} & P. aeruginosa & Seftazidim & $3 \times 1000 \mathrm{mg}$ & 5 & Sefepim & Kolistin \\
\hline & & Kolistin & $2 \times 75 \mathrm{mg}$ & & \multicolumn{2}{|c|}{ Seftazidim } \\
\hline \multirow[t]{2}{*}{31} & P. aeruginosa & Siprofloksasin & $2 \times 400 \mathrm{mg}$ & 20 & Netilmisin & Gentamisin \\
\hline & & Meropenem & $3 \times 1000 \mathrm{mg}$ & & Siprofloksasiı & Amikasin \\
\hline \multirow[t]{4}{*}{41} & S. lentus & Linezolid & $2 \times 600 \mathrm{mg}$ & 11 & Quinupristin/1 & alforpristin \\
\hline & & & & & Teikoplanin & Vancomisin \\
\hline & & & & & Linezolid & Fusidik asit \\
\hline & & & & & Tigesiklin & Daptomisin \\
\hline \multirow[t]{2}{*}{52} & P. fluorescens & Merapenem & $3 \times 1000$ gr $2 \times 80$ & 10 & Gentamisin & Kolistin \\
\hline & & Gentamisin & $\mathrm{mg}$ & & \multicolumn{2}{|c|}{ Amikasin } \\
\hline \multirow[t]{6}{*}{87} & C. lapagei & Tigesiklin & $1 \times 100 \mathrm{mg} 2 \times 15$ & 13 & \multirow{7}{*}{\multicolumn{2}{|c|}{$\begin{array}{c}\text { Trimetoprim/Sülfametoksazol } \\
\text { Amoksisilin/Klavulanik asit } \\
\text { Piperasilin/Tazobaktam } \\
\text { Tigesiklin } \\
\text { Piperasilin } \\
\text { Ampisilin } \\
\text { Piperasilin/Tazobaktam }\end{array}$}} \\
\hline & & Kolistin & $\mathrm{mg}$ & 4 & & \\
\hline & & Amikasin & $1 \times 1000 \mathrm{mg}$ & 9 & & \\
\hline & & & & & & \\
\hline & & & & & & \\
\hline & & & & & & \\
\hline 91 & P. fluorescens & Piperasilin/Tazobaktam & $3 \times 4500 \mathrm{mg}$ & $3 *$ & & \\
\hline
\end{tabular}


evre orofarenks skuamöz hücreli karsinom tanılı hastada gözlenen C. Lapagei enfeksiyonu sunulmuştur.

Literatür bilgileri incelendiğinde Cedecea türlerinin izole edilmiş olduğu hastaların çoğunun ileri yaşta ve bağışıklık sisteminin baskılandığ 1 kronik sistemik bir hastalığa sahip oldukları görülür $(1-3,7,8)$. Ancak Cedecea türlerinin klinik önemi henüz netleşmemiştir (1-10). Buna karşın hangi Cedecea türünün enfeksiyona neden olduğunun doğru bir şekilde gösterilmesi önerilir (7).Cedecea türlerinden C.davisae ve C.neteri ile ilgili olarak bildirilen olguların C.lapagei ile oluşan enfeksiyonlardan anlamlı ve net bir farkı yoktur denilebilir (2-8). Tüm bu Cedecea türlerinin hastanede yatan diyabet, kanser, kronik renal yetmezlik, kronik obstruktif akciğer hastalığ ve karaciğer yetersizliği gibi ciddi, sistemik kronik hastalıklarda izole edilmesi oldukça önem taşır (28). Ancak bu zamana kadar nazokomiyal bir enfeksiyon olarak tanımlanmamıştır $(1,9)$. Buna karşın Pande ve ark. tarafindan yapılan bir çalışmada \%50'nin üzerinde bir oranda tarımsal
Klinik önemi henüz net olmasa da özellikle immunsüpresyonu olan hastalarda mortalite nedeni de olabilen Cadecea Lapagei enfeksiyonları ile ilgili Türkiye'den şu ana kadar toplam 4 olgu bildirilmiştir (10-13). Bu olgulardan 2'si pnömoni, 1'i idrar yolu enfeksiyonu ve 1'i de bakteriyemi olarak raporlanmıştır (10-13). Tüm literatür bilgileri incelendiğinde Cadecea Lapagei’nin izole edilmiş olduğu enfeksiyon olgularının tamamı Tablo 2'de özetlenmiştir (10-22).

Son zamanlarda Cadecea Lapagei ve diğer Cadecea türleri ile ilişkili hastaların literatürde daha sik yer alması ilerde bu bakterinin tedavisinin ve klinik öneminin daha iyi anlaşılır hale geleceğini düşündürebilir.

Hasta Onamı: Hastanın verilerini bilimsel yazılarda kullanmaya dair onamı 01.04.2016 tarihnde alınmıştır.

Tablo 2. Literatürde Cadecea Lapagei'nin izole edilmiş olduğu olgu sunumları

\begin{tabular}{|c|c|c|c|c|c|}
\hline Yll & Yaş-Cinsiyet & Komorbidite & Enfeksiyon tanısı & Üreme Yeri & Kaynak \\
\hline 2008 & $38 / \mathrm{E}$ & KOAH, subaraknoid kanama & Pnömoni & Bronkoalveoler lavaj & Yetkin ve ark (10) \\
\hline 2014 & $18 / \mathrm{E}$ & - & Pnömoni & Trakeal aspirat & Ağca ve ark (11) \\
\hline 2014 & $40 / \mathrm{E}$ & - & İdrar yolu enfeksiyonu & İdrar & Çekin ve ark. (12) \\
\hline 2018 & $85 / \mathrm{K}$ & Hepatosellüler karsinom & Bakteriyemi & Kan & Kaya-Hassu ve ark. (13) \\
\hline 2006 & - & Karaciğer transplant & Peritonit & Periton s1v1S1 & Davis et al (14) \\
\hline 2008 & $47 / \mathrm{E}$ & Diyabet & $\begin{array}{l}\text { Yara yeri enfeksiyonu } \\
\text { (yanık) }\end{array}$ & Yara yeri & Dalamaga et al (15) \\
\hline 2013 & - & Akut lösemi & Pnömoni & Balgam & Lopez et al (16) \\
\hline 2013 & $24 / \mathrm{E}$ & - & Yara yeri enfeksiyonu & Ülsere ayak lezyonu & Salazar et al (17) \\
\hline 2015 & $50 / \mathrm{E}$ & $\begin{array}{l}\text { Bukkal skuamöz hücreli } \\
\text { karsinom }\end{array}$ & Yara yeri enfeksiyonu & Ülsere bukkal lezyon & Biswal et al (18) \\
\hline 2015 & $47 / \mathrm{E}$ & Bilinmiyor & Osteomiyelit & Kemik dokusu & Cardenas JL (19) \\
\hline 2015 & $76 / \mathrm{E}$ & $\mathrm{KOAH}$ & Pnömoni & Balgam & Hong et al (20) \\
\hline 2016 & $67 / K$ & KOAH & Pnömoni & Bronşiyal aspirat ve kan & Aguilar et al (21) \\
\hline 2017 & Yenidoğan/E & - & Pnömoni & Trakeal aspirat ve kan & Kurry et al. (22) \\
\hline 2018 & $52 / \mathrm{E}$ & $\begin{array}{l}\text { Karaciğer sirozu, } \\
\text { hipertansiyon }\end{array}$ & $\begin{array}{l}\text { Yumuşak doku } \\
\text { enfeksiyonu, sepsis }\end{array}$ & Kan & Herrera et al (23) \\
\hline
\end{tabular}

tozlardan izole edilen Enterobacteriaceae ailesi bakterilerin sadece \%0.7'sinin Cedecea türleri olduğu bildirilmiştir (9). $\mathrm{Bu}$ nedenle Cedecea türleri için çevresel rezervlerin tarımsal tozlar veya sıvılar olduğu düşünülmüştür $(1,9-11)$.

Cedecea türlerinin antimikrobiyal tedavisinin çoğunlukla önemli bir sorundur. Öncesinde polimikrobiyal enfeksiyon olsun ya da olmasın bir çok antimikrobiyal ilaca dirençli olmaları bunun em önemli nedeni olarak bildirilmiștir (6-10). Sıklıkla birinci nesil sefalosporinlerden sefalotin, ampisilin, kolistin ve ikinci nesil sefalosporinlerden sefoksitin Cedecea türlerinin dirençli oldukları antimikrobiyal ajanlardır $(10,11)$.

\section{Kaynaklar}

1. Abbott SL. Klebsiella, Enterobacter, Citrobacter, Serratia, Plesiomonas, and other Enterobacteriaceae, pp: 684- 700. In: Murray PR, Baron EJ, Jorgensen JH, Pfaller MA, Yolken RH (eds), Manual of Clinical Microbiology. 2003, 8th ed. ASM Press, Washington, D.C.

2. Mawardi H, Pavlakis M, Mandelbrot D, Woo SB. Sirolimus oral ulcer with Cedecea davisae superinfection. Transpl Infect Dis. 2010;12:446-50.

3. Perkins R, Beckett TA, Bump CM. Cedecea davisae bacteremia. J Clin Microbiol. 1986;24(4):675-6.

4. Farmer JJ, Sheth NK, Hudzinski JA, Rose HD, Asbury MF. Bacteremia due to Cedecea neteri sp. nov. J Clin Microbiol. 1982;16(4):775-8. 
5. Dalamaga M, Pantelaki M, Karmaniolas K, Matekavits A, Daskalopoulou K. Leg ulcer and bacteremia due to Cedecea davisae. Eur J Dermatol. 2008;18(2):204-5.

6. Farmer JJ 3 rd, Sheth NK, Hudzinsky JA, Rose HD, Asbury MF. Bacteremia due to Cedecea neteri sp. nov. J Clin Microbiol. 1982;16:775-8.

7. Aguilera A, Pascual J, Loza E, , et al. Bacteremia with Cedecea neteri in a patient with systemic lupus erythematosus. Postgrad Med J. 1995;71:179-80.

8. Bae BH, Sureka SB. Cedecea davisae isolated from scrotal abscess. J Urol. 1983;130:148-9.

9. Pande BN, Krysinska-Traczyk E, Prazmo Z, Skorska C, Sitkowska J, Dutkiewicz J. Occupational biohazards in agricultural dusts from India. Ann Agric Environ Med. 2000;7:133-9.

10. Yetkin G, Ay S, KayabasU, Gedik E, GucluerN, Caliskan A. A pneumonia case caused by Cedecea lapagei. Mikrobiyol Bul. 2008;42:681-4.

11. Ağca H, Bozkurt M. A pneumonia case caused by Cedecea Lapagei. J Clin Anal Med. 2014:5:147-8

12. Cekin Y, Kizılates F, Dolu S, Öztoprak N, Cekin AH. The first urinary tract infection caused by Cedecea lapagei: a case report and review of the literature. Gaziantep Med J. 2014;20:193-5.

13. Hassu Ö, Çelik İ. An Uncommon Cause of Bacteremia: Cedacia lapagei. Flora. 2018;23(2):88-91.

14. Davis O, Wall BM. "Broom straw peritonitis" secondary to Cedacia lapagei in a liver transplant recipient. Perit Dial Int. 2006;26(4):512-3.
15. Dalamaga M, Karmaniolas K, Arsenis G, et al. Cedecea lapagei bacteremia following cement-related chemical burn injury. Burns. 2008;34(8):1205-7.

16. Lopez LA, Ibarra BS, de La Gorza JA, Nunez AI, Lopez MB. First reported case of pneumonia caused by Cedecea lapagei in America. Braz J Infect Dis. 2013;17(5):626-8.

17. Salazar G, Almeida A, Gomez M. Cedecea lapagei traumatic wound infection: case report and literature review. Rev Chilena Infectol. 2013;30(1):86-9.

18. Biswal I, Hussain NA, Grover RK. Cedecea lapagei in a patient with malignancy: Report of a rare case. J Can Res Ther. 2015;11:646.

19. Cardenas JL. Acute osteomyelitis by Cedecea lapagei. Acta Med Colomb. 2015;40(3):246-8.

20. Hong SK, Lee JS, Kim EC. First Korean case of Cedecea lapagei pneumonia in a patient with chronic obstructive pulmonary disease. Korean J Lab Med. 2015;35:266-8.

21. Aguilar GA, Basurta AL, Luna AG, Esquivel VHN, Barajas JAS. Cedecea lapagei bacteremia: a case report in Mexico. Acta Medica Grupo Angeles. 2016;14(3):176-8.

22. Kurry CMH, Yabrudi AA, de Souza TB, et al. First reported case of ventilator-associated pneumonia and sepsis caused by Cedecea lapagei in a Brazilian Neonatal Intensive Care Unit. J Pediat Inf Dis. 2017;6(2):209-10.

23. Herrera VRC, de Silva MFR, Alcanaz HO, Espiritu GC, Pena KC, Melnikov V. Death rrelated to Cedecea lapagei in a soft tissue bullae infection. A case report. J Med Case Rep 2018;12:328. 